\title{
WET TROPOSPHERIC CORRECTION'S IMPACT ON SEA LEVEL ANOMALY AROUND THE INDONESIAN SEAS
}

\author{
Eko Yuli Handoko \\ Department of Geomatics Engineering \\ Institut Teknologi Sepuluh Nopember, Kampus ITS Sukolilo, Surabaya 60111, Indonesia \\ e-mail: ekoyh@geodesy.its.ac.id
}

\begin{abstract}
Global sea level rise in the satellite altimetry era is about $3 \mathrm{~mm} / \mathrm{yr}$. The one of main source of uncertainty of global sea level is the wet tropospheric from onboard microwave radiometer which is up to $0.3 \mathrm{~mm} / \mathrm{yr}$. The focus of this study is to assess of various wet tropospheric correction impact on sea level anomaly in the Indonesian seas. The result of sea level anomaly linear trend difference between Global Navigation Satellite System and Microwave Radio Meter or ECMWF Re-Analysis Interim is $0.18 \mathrm{~mm} / \mathrm{yr}$ in agreement with the global wet tropospheric uncertainty.
\end{abstract}

Keywords: wet tropospheric correction, sea level anomaly, microwave radiometer, ECMWF re-analysis, Indonesian seas

\section{INTRODUCTION}

The long-term sea level change is an indicator for climate change and variability due to its close relation with the ocean, cryosphere, hydrosphere and atmosphere systems. According to the Fifth Assessment Report (AR5) of the Intergovernmental Panel on Climate Change (IPCC), the projection of sea level rise in 2100 ranges from 44 to $74 \mathrm{~cm}$ (Church et al., 2013). This prediction may be an important sign, particularly for countries located in low-lying areas. Sea level change is likely to have a significant impact on socio-economics, infrastructure and environment due to land-loss, particularly in the coastal areas where human activities are more concentrated. Sea level rise can cause inundation of low-lying coastal, extreme sea level, flooding, salt seawater intrusion into surface water and aquifers (Nicholls dan Cazenave, 2010; Poerbandono, Handoko dan Adytia, 2018).

Globally, sea level has been rising up to $3.4 \mathrm{~mm} /$ year according to the satellite altimetryderived (Ablain et al., 2015). However, sea level is not rising uniformly across the globe. Some areas have higher rates of sea level variation, such as the Southern Indian Ocean and the Western Pacific Ocean (Church et al., 2006).

Regarding the global mean sea level (GMSL) trend, an uncertainty of $0.5 \mathrm{~mm} /$ year was estimated over the satellite era (1993 - 2015) within a confidence interval of 95\% (Ablain et al.,
2016). The radiometer wet tropospheric correction (WTC) is one of the main error sources affecting the mean sea level with a drift uncertainty in range of $0.2-0.3 \mathrm{~mm}$ /year (Ablain et al., 2009; Legeais et al., 2014). This correction is potentially contaminated by long-term instrumental drift, such as the changes of internal temperature due to yaw maneuvers (Desain dan Haines, 2004; Scharroo et al., 2004). Calibrations with external measurements are periodically performed to detect drifts on the on-board microwave radiometers (MWR). The algorithms used to retrieve the WTC from the measured brightness temperatures of the various MWR channels assume a constant surface ocean emissivity and are valid for ocean conditions, light rain and wind speed lower than $20 \mathrm{~ms}^{-1}$. Therefore, in the presence of surfaces with different emissivity (such as land or ice) the measurements become invalid, particularly in coastal and Polar Regions (Fernandes et al., 2015).

In the open ocean, the WTC can be retrieved within a few $\mathrm{cm}$ accuracy using on-board microwave radiometers. However, this does not proper to the coastal regions. The differences between ocean emissivity (around 0.5) and land emissivity (around 0.9) cause the radiometer footprint, as it approaches the coast, to contain portions of surfaces with different emissivity. Therefore, the WTC ocean retrieval algorithm originates invalid measurements in the regions close to the coast or land. 
As an alternative to the WTC from onboard microwave radiometers, a number of atmospheric models, such as European Centre for Medium-Range Weather Forecasts (ECMWF) and National Centers for Environmental Prediction (NCEP), which provide data on regular grids, can be used to derive tropospheric path delays. Another method for deriving WTC can use the Global Navigation Satellite System (GNSS) data. Apart from determining the position and time, the GNSS allows the determination of zenith total delays at station height with an accuracy of a few millimeters (Fernandes et al., 2010; 2013; 2015).

Considering impact of WTC on sea level variability particularly in coastal region, the objective of this study is to assess of various WTC in determination of sea level variability in the Indonesian seas.

\section{STUDY AREA: INDONESIAN SEAS}

Indonesia is characterized by its unique geographical and geophysical setting. Indonesia consists more than 17,000 islands, 5.8 million $\mathrm{km}^{2}$ of sea area and $81,000 \mathrm{~km}$ of coastline. The Indonesian seas are the oceanic pathway for the Pacific and Indian inter-ocean exchange; it is called the Indonesian Throughflow (ITF) (Gordon, 2005). The ITF brings warm and fresh water from the west Pacific Ocean into the southeast Indian Ocean through the passages between the islands of the Indonesian archipelago. the Makassar Strait is a primary inflow and outflow through the Lombok Strait directly to Indian Ocean and through the Banda Sea, the Flores Sea, the Ombay Strait and the Timor Passage before goes to the Indian Ocean (Sprintall et al., 2014). The fresh water and low-salinity from the South China Sea (SCS) flows through the Karimata Strait and the Java Sea; thus mixing into the primary ITF inflow in the southern Makassar Strait (Wei et al., 2016).

The tropical Pacific and Indian Ocean regions have high sea level variability associated with atmosphere-ocean phenomena such as the ENSO, the Indian Ocean Dipole (IOD) and the Asian-Australian monsoon (Church dan White, 2006; England dan Huang, 2005). The Indonesian seas, located between the Pacific and Indian oceans are strongly impacted by ENSO (Handoko et al., 2017).
The study area is in the Indonesian seas for the latitude range $20^{\circ} \mathrm{N}-20^{\circ} \mathrm{S}$ and longitude range $90^{\circ} \mathrm{E}-150^{\circ} \mathrm{E}$ and covers all the Indonesia seas surrounded by the west Pacific Ocean, the eastern Indian Ocean and the South China Sea (shown at Figure 1).

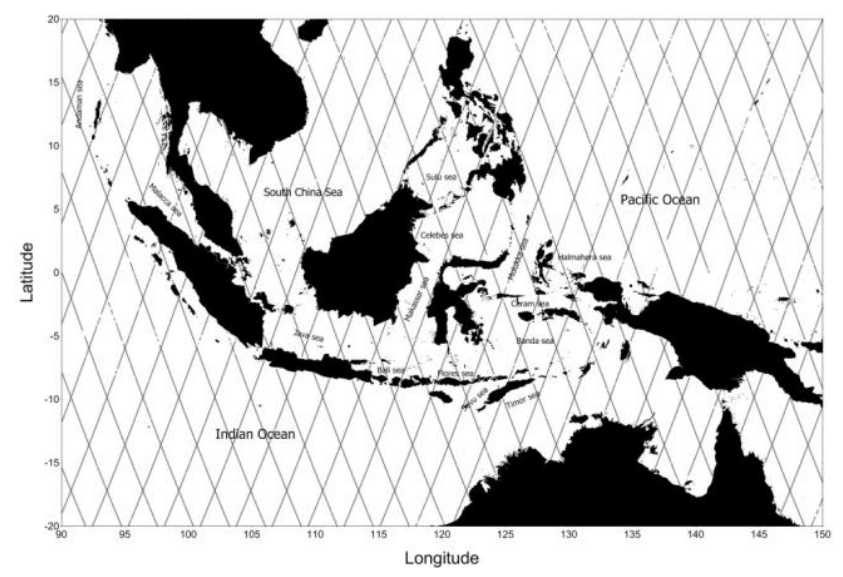

Figure 1. Along-tracks of TOPEX/Poseidon, Jason-1 and Jason-2 altimeter over the Indonesian seas

\section{SEA LEVEL ANOMALY}

The era of satellite altimetry carried out a revolution in sea level measurement. TOPEX/Poseidon (T/P), Jason-1, Jason-2 and Jason3 measure the entire global sea level up to $\pm 66^{\circ}$ latitudes in 9.99 days, providing precise and continuous datasets for sea level studies with global coverage and moderate spatiotemporal resolution.

A satellite altimeter measures the vertical range between the satellite and the sea surface. It transmits a short pulse of microwave radiation from the on-board radar antenna toward the sea surface, part of the signal being reflected back to the satellite. By measuring the two-way travel time of the signal, the range can be determined. Thus, the sea-surface height (SSH) is obtained by the difference between the satellite height above the reference ellipsoid and the range of the satellite to the sea surface.

However, several corrections have to be applied to the observed altimeter range, before it can be used to determine the sea surface height (SSH). For studies of sea surface height variations, it is often more convenient to refer the sea surface height to the mean sea surface height rather than to the geoid, thus generating the sea level anomalies (SLA) (Andersen and Scharroo, 2011). By subtracting the mean sea surface from $\mathrm{SSH}$, the 
temporal mean of the dynamic sea surface height is removed.

The determination of SLA from altimeter measurements requires the correction for all instrument, range and geophysical corrections. SLA is estimated as follows:

$h_{\text {SLA }}=H-R-\Delta h_{\text {dry }}-\Delta h_{\text {wEt }}-\Delta h_{\text {iono }}-\Delta h_{\text {SSB }}-$ $h_{\text {DAC }}-h_{\text {tides }}-h_{\text {mss }}$

where $H$ is satellite height above a reference ellipsoid, $R$ is corrected altimeter range (including instrumental effect), $\Delta h_{\text {dry }}$ (dry tropospheric correction), $\Delta h_{\text {wet }}$ (wet tropospheric correction), $\Delta h_{\text {iono }}$ (ionospheric correction) and $\Delta h_{S S B}$ (sea state bias) are range corrections due to the interaction between the radar signal with the atmosphere and with the sea surface, $h_{D A C}$ (dynamic atmospheric correction) and $h_{\text {tides }}$ (tides: ocean, load, solid earth, and pole) are corrections related with geophysical phenomena. All values must be given in a fixed coordinate system based on a mathematical determinable ellipsoid model of the Earth.

\section{WET TROPOSPHERIC CORRECTION}

For the long-term estimation of sea level, it is important to ensure the consistency and stability of altimetry measurements. One factor that causes uncertainty in satellite altimetry is the path delay due to water vapor in the atmosphere; this is called WTC.

The wet troposphere path delay affects the altimeter range. Although the absolute value of the WTC is only about $50 \mathrm{~cm}$, it has high variability, both in space and time, thus not being easy to model; it needs more attention in order to estimate the wet troposphere path delay with enough accuracy for satellite altimetry. The maim problems of the wet path delay modeling in altimeter studies mostly occur at coastal regions. The land's effect on the radiometerderived wet tropospheric correction decreases the accuracy of this correction in these regions. The discrepancy of the emissivity between ocean and land on the altimeter footprint near the coast causes the algorithms used to retrieve the WTC to output invalid measurements.

\section{WTC from on-board Microwave Radiometer, Numerical Weather Model and GNNS}

The wet tropospheric correction is computed from the onboard MWR of satellite altimeter by measuring the brightness temperature (TBs) at two or three frequencies in the range of 18 and $37 \mathrm{GHz}$, in spectral bands sensitive to water vapor and cloud liquid water. TOPEX/Poseidon carried the three-channel TOPEX Microwave Radiometer (TMR), which operated at 18, 21 and $37 \mathrm{GHz}$. Meanwhile, Jason-1 brought the Jason-1 Microwave Radiometer (JMR) and Jason-2 carries the Advanced Microwave Radiometer (AMR) which operates at 18.7, 23.8 and $34 \mathrm{GHz}$. The algorithm for the TMR/JMR/AMR performs the retrieval in three steps: (1)a term analogous to a surface "radiometer wind" and a term due to cloud liquid water are estimated using a linear combination of the TBs from the 3 channels; (2) a first approximation of the wet path delay is estimated; (3) the wet path delay is obtained by adding to the cloud liquid water term, a term obtained from a log-linear combination of the TBs from the 3 channels, with coefficients depending on the "radiometer wind" and wet path delay class interval obtained in the first two steps (Keihm and Ruf, 1995).

WTC also can be determined using global atmospheric model data, such as ECMWF which provides two of global $0.125^{\circ} \times 0.125^{\circ}$ grids for the Operational model and $0.75^{\circ} \times 0.75$ o grids for ERA Interim of several atmospheric parameters every 6 hours and NCEP (Dee et al., 2011). Both models provide global grids of sea level pressure, total column water vapor (TCWV) and surface temperature (2-m temperature, 2T). These parameters can be used to compute the wet tropospheric correction.

The following equation is usually used to estimate WTC as is a function of various physical constants and of the weight mean temperature $T_{m}$ of the atmosphere. The WTC can be estimated from TCWV and $T_{m}$ using the equation (Bevis et al., 1994):

$W T C=-\left(0.101995+\frac{1725.55}{T_{m}}\right) \frac{\text { TCWV }}{1000}$

$T_{m}=50.40+0.789 T_{0}$ 
where $T_{m}$ is the mean temperature of the troposphere, which may be in turn modeled from the surface temperature $\left(T_{0}\right)$ (Mendes et al., 2000), TCWV is the total water vapor contained in an air column from the Earth's surface to the top of the atmosphere and is usually expressed in $\mathrm{kg} / \mathrm{m}^{2}$ or millimeters $(\mathrm{mm}), T_{0}$ in kelvin, TCWV in millimeters and WTC in meters.

Aiming at reducing the WTC errors, particularly in coastal regions where the on-board microwave radiometer measurements become invalid due to land contamination in the radiometer footprint, the Global Navigation Satellite System (GNSS)derived Path Delay (GPD+) algorithm was proposed by the University of Porto, Portugal (Fernandes et al., 2010). The GNSS-derived Path Delays (GPD+) methodology is based on the combination, by objective analysis (OA), of wet path delay observations from various sources (valid MWR measurements at the nearby points and ZWD derived from GNSS datasets), to update a first WTC guess value given by an atmospheric model, more detail please see Fernandes dkk (2015).

\section{ASSESSMENT OF WTC ON SEA LEVEL ANOMALY}

To assess the various wet tropospheric corrections, the analyses of the coastal effects on satellite altimetry using SLA variance were performed. The assessment was based on SLA variance analyses, in particular along-track analysis function of distance from the coast.

The assessment of the WTC has been performed by means of a set of statistical analyses of SLA variance: SLA along-track variance differences; weighted mean values per cycle (weights function of the co-sine of latitude) and at collocated points function of distance from the coast. SLA WTC datasets are first derived, for each cycle, using the standard geophysical corrections under comparison, for detail see in Handoko, Fernandes, Lazaro (2017). Then, the difference between the variance of each SLA WTC dataset, computed using all along-track points, is estimated for each cycle. The variance of collocated along-track SLA measurements for a given period and using each WTC is computed in bins of distance from coast and then the differences considered.

In this paper, Altimeter data were used: TOPEX/Poseidon (cycles 11-353), Jason-1 (cycles 11-248) and Jason-2 (cycles 10-312), SLA was determined for 24 years period (1993-2016). Data altimeter (TOPEX/Poseidon, Jason-1 and Jason-2) have been extracted from the Radar Altimeter Database System (RADS).

In order to assess the quality of various WTC on altimeter data, analyses of SLA variance, derived from different datasets, has been performed. Based on Equation (1), SLA datasets have been computed using parameters as shown in Table I.

TABLE 1 Selected range and geophysical corrections and mean sea surface model for determining SLA around the Indonesian seas

\begin{tabular}{|c|c|c|c|c|}
\hline \multirow[t]{2}{*}{ Parameter } & \multicolumn{4}{|l|}{ Missions } \\
\hline & TOPEX/Poseidon & & Jason-1 & Jason-2 \\
\hline Year & $1993-2002$ & & $2002-2008$ & $2008-2016$ \\
\hline Cycles & 011-353 & & $011-248$ & 010-312 \\
\hline Dry Troposphere & ERA-Interim & & ERA-Interim & ERA-Interim \\
\hline Wet Troposphere & ERA/MWR/GPD+ & & ERA/MWR/GPD+ & ERA/MWR/GPD+ \\
\hline Ionosphere & $\begin{array}{l}\text { Smoothed } \\
\text { Frequency }\end{array}$ & Dual & $\begin{array}{l}\text { Smoothed } \\
\text { Frequency }\end{array}$ & $\begin{array}{l}\text { Smoothed } \\
\text { Frequency }\end{array}$ \\
\hline Sea state Bias & CLS & & Tran2012 Model & Tran2012 Model \\
\hline Ocean \& Load tide & GOT 4.10 & & GOT 4.10 & GOT 4.10 \\
\hline Mean Sea Surface & CNES CLS 2011 & & CNES CLS 2011 & CNES CLS 2011 \\
\hline
\end{tabular}


Figure 2 illustrates the SLA variance differences of WTC $\left(\mathrm{cm}^{2}\right)$, function of distance from coast, GPD+ - ERA Interim (orange), GPD+ - MWR (blue) and ERA - MWR (cyan). This figure shows that for TOPEX/Poseidon, the wet tropospheric correction from GPD+ reveals a significant improvement with respect to the MWR correction present in RADS, particularly near the coast for distances less than $25 \mathrm{~km}$ and still has a small improvement with respect to ERA-Interim (less than $2 \mathrm{~cm}^{2}$ ). This is due to the presence of land contaminated and erroneous measurements due to instrument improperness present in TOPEX/Poseidon data. The GPD+ WTC reduces the SLA variance with respect to the ERA model (about $6 \mathrm{~cm}^{2}$ ) for Jason1 and Jason-2. Regarding the comparison with the MWR-derived WTC, for Jason-1, the GPD+ correction shows a significant improvement (average differences of $4 \mathrm{~cm}^{2}$ ) and ERA correction does not show an improvement. GPD+ correction shows a smaller improvement (less than $3 \mathrm{~cm}^{2}$ ) for Jason-2 and MWR has an improvement with respect to ERA-Interim due to already has improvement for coastal regions (Brown, 2010).
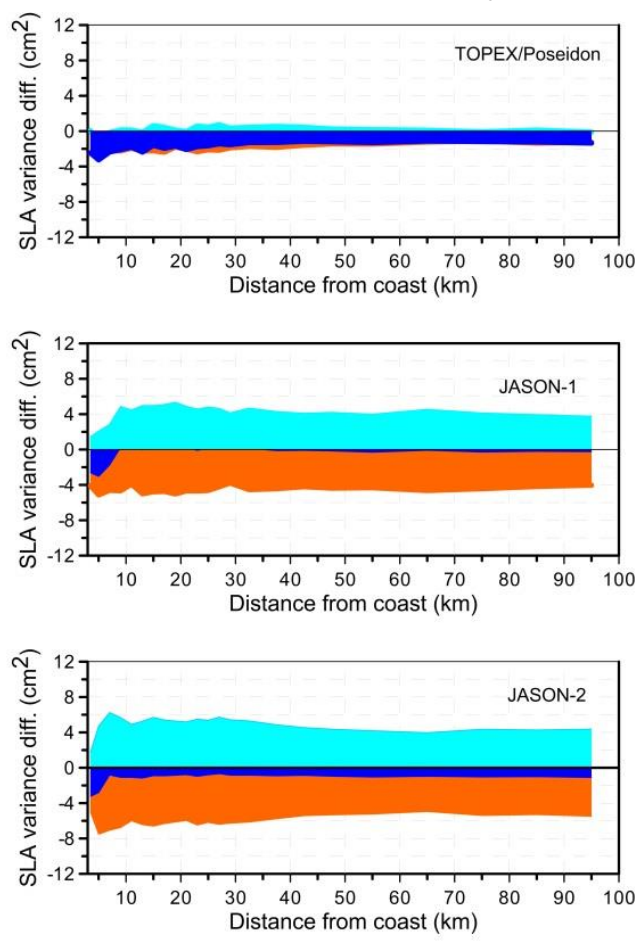

WTC GPD - ERA

WTC GPD - MWR

WTC ERA - MWR

Figure 2. SLA variance differences of WTC (units in $\mathrm{cm} 2$ ) function of distance from coast, $S L A_{G P D+}-S_{L A R A}$ (orange), $S L A_{G P D+}-S L A_{M W R}$ (blue), and SLA ERA - SLA $A_{M W R}$ (cyan)

The trend and seasonal signal effects were modelled using a Seasonal-Trend Decomposition Procedure based on Loess (STL) (Cleveland et al., 1990). It can be observed that these series are significantly different from the global one. SLA time series have been smoothed prior to the signal decomposition to account for the 59-day signal apparent in the GMSL record. Finally, the linear sea level trend was determined by original least squares (OLS) of the inter-annual signal.

The linear trends of SLA from GPD+, ERA-Interim and MWR are $6.57 \mathrm{~mm} / \mathrm{yr}, 6.39 \mathrm{~mm} / \mathrm{yr}$ and 6.39 $\mathrm{mm} / \mathrm{yr}$, respectively. SLA linear trend differences among GPD+ and ERA-Interim or MWR are 0.18 $\mathrm{mm} / \mathrm{yr}$. The uncertainty of global mean sea level due to WTC impact is less than $0.3 \mathrm{~mm} /$ year (Ablain et al., 2009; Legeais et al., 2014). 


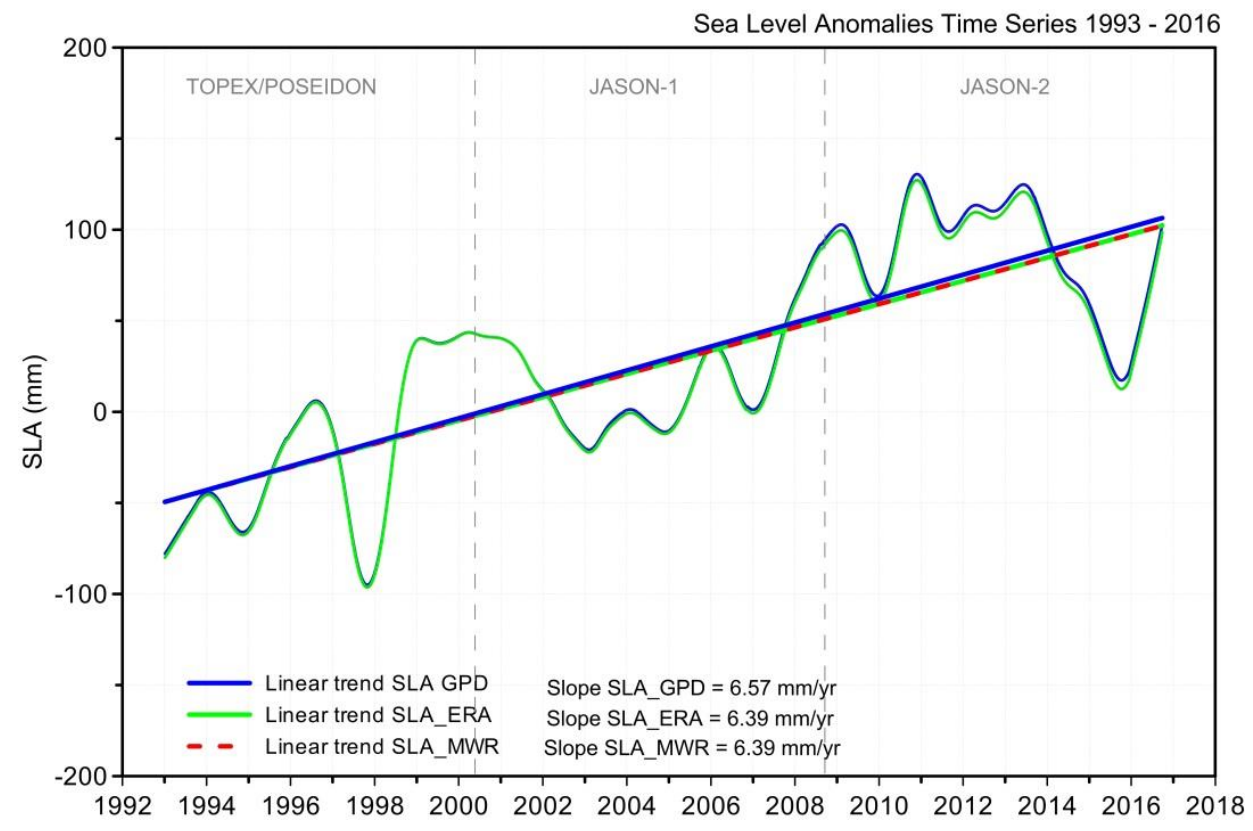

Figure 3. Inter-annual and linear trend comparison of various SLA: SLA $A_{\text {GPD+ }}$ (blue line), SLA $\mathrm{SLA}_{\mathrm{MWR}}$ (red dash line)

\section{CONCLUSIONS}

In this study, the assessment of various WTC has been performed for the Indonesia seas using TOPEX/Poseidon, Jason-1 and Jason-2 data for a period of 24 years. Table 1 shows the selected set for the various range and geophysical corrections and mean sea surface models, which were used to estimate the SLA time series for this region.

For most of Satellite altimetry missions, the GPD+ corrections reduce the SLA variance when compared to Microwave Radiometer (MWR) and ERA-Interim, particularly in the coastal zone. This

\section{ACKNOWLEDGMENTS}

The author would like to thank for Dr. Joana

Fernandes and Dr. Clara Lazaro from University of

\section{REFERENCES}

Ablain, M., Legeais, J. F., Prandi, P., Marcos, M., Fenoglio-Marc, L., Dieng, H. B., . . . Cazenave, A. (2016). Satellite AltimetryBased Sea Level at Global and Regional Scales. Surveys in Geophysics, 38(1), 7-31. doi:10.1007/s10712-016-9389-8

Ablain, M., Cazenave, A., Valladeau, G., \& Guinehut, S. (2009). A new assessment of the error budget of global mean sea level is expected since GPD+ is based on actual observations, not only from the on-board MWR but also from GNSS and SI-MWR.

Results show the effect of using different WTC in the computation of SLA time series. The SLA time series derived WTC from GPD+, ERA-Interim and Microwave Radiometer (MWR) are $6.57 \mathrm{~mm} / \mathrm{yr}$, $6.39 \mathrm{~mm} / \mathrm{yr}$ and $6.39 \mathrm{~mm} / \mathrm{yr}$, respectively. The difference of SLA linear trend is $0.18 \mathrm{~mm} / \mathrm{yr}$ in agreement with a drift uncertainty of global mean sea level affected by WTC.

Porto, Portugal, for discussion and providing GPD data, and the Radar Altimeter Database System (RADS) for providing the altimetry data

rate estimated by satellite altimetry over 1993-2008. Ocean Science, 5, 193-201.

Andersen, O. B., \& Scharroo, R. (2011). Range and Geophysical Corrections in Coastal Regions: And Implications for Mean Sea Surface Determination. In S. Vignudelli, A. G. Kostianoy, P. Cipollini, \& J. Benveniste (Eds.), Coastal Altimetry (pp. 103-145). Berlin Heidelberg: Springer-Verlag. 
Bevis, M., Businger, S., Chiswell, S., Herring, T. A., Anthes, R. A., Rocken, C., \& Ware, R. H. (1994). GPS Meteorology: Mapping Zenith Wet Delays onto Precipitable Water. Jounal of Applied Meteorology, 33, 379-386.

Brown, S. (2010). A Novel Near-Land Radiometer Wet Path-Delay Retrieval Algorithm: Application to the Jason-2/OSTM Advanced Microwave Radiometer. IEEE Transactions on Geoscience and Remote Sensing, 48(4), 1986-1992. doi:10.1109/tgrs.2009.2037220

Church, J. A., Clark, P. U., Cazenave, A., Gregory, J. M., Jevrejeva, S., Levermann, A., . . . Unnikrishnan, A. S. (2013). Sea Level Change. In T. F. Stocker, D. Qin, G.-K. Plattner, M. Tignor, S.K. Allen, J. Boschung, A. Nauels, Y. Xia, V. Bex and P.M. Midgley (Ed.), Climate Change 2013: The Physical Science Basis. Contribution of Working Group I to the Fifth Assessment Report of the Intergovernmental Panel on Climate Change (pp. 1137-1216). Cambridge, United Kingdom and New York, NY, USA: Cambridge University Press.

Church, J. A., White, N. J., \& Hunter, J. R. (2006). Sea-level rise at tropical Pacific and Indian Ocean islands. Global and Planetary Change, 53(3), 155-168. doi:10.1016/j.gloplacha.2006.04.001

Cleveland, R. B., Cleeland, W. S., McRae, J. E., \& Terpenning, I. (1990). STL: a Seasonal-Trend Decomposition Procedur Base on Loess. Journal of Official Statistics, 6(1), 3-73.

Dee, D. P., Uppala, S. M., Simmons, A. J., Berrisford, P., Poli, P., Kobayashi, S., . . . Vitart, F. (2011). The ERA-Interim reanalysis: configuration and performance of the data assimilation system. Quarterly Journal of the Royal Meteorological Society, 137(656), 553-597. doi:10.1002/qj.828

Desai, S. D., \& Haines, B. J. (2004). Monitoring Measurements from the Jason-1 Microwave Radiometer and Independent Validation with GPS. Marine Geodesy, 27(1-2), 221240. doi:10.1080/01490410490465337

England, M. H., \& Huang, F. (2005). On the Interannual Variability of the Indonesian Throughflow and Its Linkage with ENSO. Journal of Climate, 18, 1435-1444.

Fernandes, M. J., Lázaro, C., Ablain, M., \& Pires, N. (2015). Improved wet path delays for all ESA and reference altimetric missions. Remote Sensing of Environment, 169, 50-74. doi:10.1016/j.rse.2015.07.023

Fernandes, M. J., Lazaro, C., Nunes, A. L., Pires, N., Bastos, L., \& Mendes, V. B. (2010). GNSSDerived Path Delay: An Approach to Compute the Wet Tropospheric Correction for Coastal Altimetry. IEEE Geoscience and Remote Sensing Letters, 7(3), 596-600. doi:10.1109/lgrs.2010.2042425

Fernandes, M. J., Pires, N., Lázaro, C., \& Nunes, A. L. (2013). Tropospheric delays from GNSS for application in coastal altimetry. Advances in Space Research, 51(8), 13521368. doi:10.1016/j.asr.2012.04.025

Gordon, A. L. (2005). Oceanography of the Indonesian Seas and Their Throughflow. Oceanography, 18 (4), 14-27.

Keihm, S., \& Ruf, C. S. (1995). Role of Water Vapor Radiometers for In-Flight Calibration of the TOPEX Microwave Radiometer. Marine Geodesy, 18, 139-156.

Legeais, J. F., Ablain, M., \& Thao, S. (2014). Evaluation of wet troposphere path delays from atmospheric reanalyses and radiometers and their impact on the altimeter sea level. Ocean Science, 10(6), 893-905. doi:10.5194/os-10-893-2014

Mendes, V. B., Prates, G., Santos, L., \& Langley, R. B. (2000, January 2000). An Evaluation of the accuracy of models of the determination of the weighted mean temperature of atmosphere. Paper presented at the Proceedings of the 2000 National Technical Meeting of The Institute of Navigation, Anaheim, CA.

Nicholls, R. J., \& Cazenave, A. (2010). Sea-level rise and its impact on coastal zones. Science, $328(5985)$, 1517-1520. doi:10.1126/science.1185782

Poerbandono, Handoko, E., \& Adytia, D. (2018). Extremes of residual water levels in the West of Java Sea, Indonesia. AIP Conference Proceedings, 1987, 020081. doi:10.1063/1.5047366

Scharroo, R., Lillibridge, J. L., Smith, W. H. F., \& Schrama, E. J. O. (2004). Cross-Calibration and Long-Term Monitoring of the Microwave Radiometers of ERS, TOPEX, GFO, Jason, and Envisat. Marine Geodesy, 
WET TROPOSPHERIC CORRECTION'S IMPACT ON SEA LEVEL ANOMALY AROUND THE INDONESIAN SEAS (EKO)

27(1-2), doi:10.1080/01490410490465265

Sprintall, J., Gordon, A. L., Koch-Larrouy, A., Lee, T., Potemra, J. T., Pujiana, K., \& Wijffels, S. E. (2014). The Indonesian seas and their role in the coupled ocean-climate system. Nature Geoscience, 7(7), 487-492. doi:10.1038/ngeo2188
279-297.
Wei, J., Li, M. T., Malanotte-Rizzoli, P., Gordon, A. L., \& Wang, D. X. (2016). Opposite Variability of Indonesian Throughflow and South China Sea Throughflow in the Sulawesi Sea. Journal of Physical Oceanography, 46(10), 3165-3180. doi:10.1175/jpo-d-16-0132.1 